www.jmscr.igmpublication.org

Index Copernicus Value: 79.54

ISSN (e)-2347-176x ISSN (p) 2455-0450

crossrefDOI: https://dx.doi.org/10.18535/jmscr/v7i2.05

\title{
Comprehend Risk of Chronic Kidney Disease (CKD) and its major Risk Factors: Results of a Health Survey in an Indian city
}

\author{
Author \\ Dr MD. Farid Alam Ansari \\ Department of Medicine, Patna Medical College \& Hospital, Patna, India \\ Email:firdausinshahasan@gmail.com
}

\begin{abstract}
Aim: Objective of this study was to assess comprehend risk for chronic kidney disease (CKD) in a community sample in Patna city of India.

Material: 200 subjects who were over the age of 21 who was willing to complete the survey and was fluent enough in English or Hindi (local language), involved at three different general medicine clinic situated at different part of Patna city. Considering varied levels of health literacy among subjects personal interview was conducted using by a predesigned questionnaire which consists of family history, quality of life, perceived risk, physician diagnosis, demographic information and perceived efficacy in the management of their health conditions. Likert-style scale or were yes/no was used for the answer of the predesigned questionnaire. 6 minutes was the estimated time to complete the questionnaire.

Result: Hypertension was diagnosed in 68 (34\%) subjects, whereas $30(15 \%)$ subjects were having type 2 diabetes and $8(4 \%)$ were identified who had a kidney disease. Most of the subjects were feeling uncontrolled of their respective diseases. A family history of both type 2 diabetes (chi $2=14.8, p<.001)$ and hypertension (chi2 $=13.3, p<.001)$ were considered themselves in high risk compared to those who doesn't had a family history of such event. Diabetes was diagnosed among 10\% of those and only $7 \%$ of those diagnosed with hypertension, both leading risk factors for kidney disease, risk factors for kidney disease was considered to be in both

Conclusion: It was found that awareness about CKD and its risk factors was extremely low among local population. Initiating awareness and education programme asymptomatic nature of CKD in its initial stages should be of prime impotence with regular renal care counselling. Lifestyle modifications and education to prevent or slow the progression of CKD should provide to individuals having high risk.
\end{abstract}

\section{Introduction}

Worldwide Chronic Kidney Disease (CKD) is considered as major health concern. Substantial morbidity and mortality were associated with CKD for many subjects ${ }^{1,2}$. In CKD diabetes (both type 1 and type 2) and hypertension is considered as major and prime risk factor 3, 4. Detection of early disease is very difficult as initial stages of $\mathrm{CKD}$ is asymptomatic. If early stage of CKD untreated or undiagnosed may gradually progress to End Stage Renal Disease (ESRD), where to sustain the patient's life costly Renal Replacement Therapy (RRT) via dialysis or renal transplantation becomes necessary 5 .

Opportunity for prevention and early treatment is decreased because of low perceived risk of kidney disease 6. Understanding a person's perceived risk for CKD is the major key factor for understanding 
and actively engaged in managing the risk factors for CKD.

Objective of this study was to assess comprehend risk for kidney disease in a community sample in Patna city of India.

\section{Material}

200 subjects who were over the age of 21 who was willing to complete the survey and was fluent enough in English or Hindi (local language), involved at three different general medicine clinic situated at different part of Patna city. Considering varied levels of health literacy among subjects personal interview was conducted using by a predesigned questionnaire which consists of family history, quality of life, perceived risk, physician diagnosis, demographic information and perceived efficacy in the management of their health conditions. Likert-style scale or were yes/no was used for the answer of the predesigned questionnaire. 6 minutes was the estimated time to complete the questionnaire. Data was collected from May 2018 through October 2018.

\section{Result}

200 subjects were involved at three different general medicine clinic situated at different part of Patna city. $71 \%$ of total population was female. Three categories of age group was involved in the study which include between 21-25 years 19 (9.5\%), 25-45 years subjects $82(41 \%)$ and 99 $(49.5 \%)$ more than 46 years.

Table 1: Descriptive Data of Sample

\begin{tabular}{|l|c|}
\hline Variable & Total Sample $(\mathrm{n}=200)$ \\
\hline Age (Years) & $19(9.5 \%)$ \\
\hline$<25$ & $82(41) \%$ \\
\hline $25-45$ & $99(49.5 \%)$ \\
\hline$>46$ & $28.6 \%$ \\
\hline Hypertension & $71.4 \%$ \\
\hline Male & $34.0 \%$ \\
\hline Female & $14.9 \%$ \\
\hline Medical History (reported physician diagnosis) \\
\hline Hypertension & $4.0 \%$ \\
\hline Diabetes & $60.3 \%$ \\
\hline Kidney Disease & \\
\hline Family Medical History & \\
\hline Hypertension & $45.1 \%$ \\
\hline Diabetes & $7.1 \%$ \\
\hline Kidney Disease & \\
\hline
\end{tabular}

Hypertension was diagnosed in 68 (34\%) subjects, whereas $30(15 \%)$ subjects were having type 2 diabetes and $8(4 \%)$ were identified who had a kidney disease. Most of the subjects were feeling uncontrolled of their respective diseases. A family history of both type 2 diabetes (chi2 $=14.8$, $\mathrm{p}<.001)$ and hypertension (chi2 $=13.3, \mathrm{p}<.001$ ) were considered themselves in high risk compared to those who doesn't had a family history of such event. Diabetes was diagnosed among $10 \%$ of those and only 7\% of those diagnosed with hypertension, both leading risk factors for kidney disease, risk factors for kidney disease was considered to be in both. $50 \%$ of individuals with high blood pressure In terms of disease management felt in control of their disease. Being in control was reported by $37 \%$ of patients having $\mathrm{T} 2 \mathrm{DM}$ and $22 \%$ of patients with kidney disease. Of those without a diagnosis of kidney disease, $10 \%$ of the sample with a family history of renal disease considered themselves at risk for kidney disease as compared to only $4 \%$ of those without a family history, although these groups were not significantly different ( $\mathrm{p}>.05)$. 10\% of individuals thought they were at increased risk for renal disease who were diagnosed diabetes but not kidney disease.

\section{Discussion}

The individuals who attended at three different general medicine clinic situated at different part of Patna city and willing to complete the survey and was fluent enough in English or Hindi (local language) were included in this trial presenting a potential bias in our sample.

Portion of our sample which is significant in number reported feeling uncontrolled of their respective diseases. The subjects who were having hypertension only half of them felt controlled and same was found in $63 \%$ of diabetics and $78 \%$ of patients with CKD. Managing a chronic disease can be unpredictable 7 and can lead to a sense of loss of control 8. Lack of control of illness may potentially be related to non-adherence ${ }^{9}$. 
Relatively low percentage of individuals view themselves at increased risk for various diseases. As compare to subjects who doesn't had any family history, patients with definite family histry were view themselves at increased risk for various diseases. The link between CKD and T2DM seems to be more known in the community than the association between hypertension and CKD. Consistent with the Health Belief Model, it is understandable why the risk factor with a lack of acute symptomatology would not result in a perception of increased risk and susceptibility for kidney disease in this sample.

\section{Conclusion}

It was found that awareness about CKD and its risk factors was extremely low among local population. Initiating awareness and education programme asymptomatic nature of CKD in its initial stages should be of prime impotence with regular renal care counselling. Lifestyle modifications and education to prevent or slow the progression of CKD should provide to individuals having high risk.

Funding: The authors report no conflicts of interest in this work. No funding sources.

\section{References}

1. Levey AS, Atkins R, Coresh J, Cohen EP, Collins AJ, Eckardt KU, et al. Chronic kidney disease as a global public health problem: approaches and initiatives - a position statement from Kidney Disease Improving Global Outcomes. Kidney Int 2007; 72: 247-59. doi: 10.1038/sj.ki.5002343

2. Tonelli M, Wiebe N, Culleton B, House A, Rabbat C, Fok M, et al. Chronic kidney disease and mortality risk: a systematic review. J Am SocNephrol 2006; 17: 203447.

3. Levey AS, Astor BC, Stevens LA, Coresh J. Chronic kidney disease, diabetes, and hypertension: what's in a name? Kidney Int 2010; 78: 19-22. doi: 10.1038/ki.2010.115

4. Levey AS, Coresh J. Chronic kidney disease. Lancet 2012; 379: 165-80. doi: 10.1016/s0140-6736(11)60178-5

5. Plantinga LC, Tuot DS, Powe NR. Awareness of chronic kidney disease among patients and providers. Adv Chronic Kidney Dis 2010; 17: 225-36. doi: 10.1053/j.ackd.2010.03.002

6. Plantinga LC, Tuot DS, Powe NR (2010) Awareness of chronic kidney disease among patients and providers. Adv Chronic Kidney Dis 17: 225-236.

7. Cukor D, Cohen SD, Peterson RA, Kimmel PL (2007) Psychosocial aspects of chronic disease: ESRD as a paradigmatic illness. J Am SocNephrol 18: 3042-3055.

8. Warren N, Canaway R, Unantenne N, Manderson L (2012) Taking control: Complementary and alternative medicine in diabetes and cardiovascular disease management. Health (London) 17: 323339.

9. Gonzalez JS, Shreck E, Psaros C, Safren SA (2015) Distress and type 2 diabetestreatment adherence: A mediating role for perceived control. Health Psychol 34: 505513. 